\title{
Signifikansi Umat Islam Indonesia Dalam Konteks Perdamaian Dunia
}

\author{
Zaedun Na'im \\ Sekolah Tinggi Agama Islam (STAI) Ma’had Aly Al-Hikam Malang \\ zaedunnaim82@gmail.com \\ Siswanto \\ Institut Agama Islam Negeri (IAIN) Curup \\ sis66505@gmail.com
}

\begin{abstract}
This discussion is about how the position of Indonesian Muslims in a global or world perspective in contributing to creating world peace in general and especially in countries with conflicts between fellow Muslim countries. It cannot be denied that the position of Indonesian Muslims from an international point of view has a strategic position, because Indonesia is a country with the largest number of Muslims in the world. So that this position has the potential and strength to be able to contribute significantly in creating world peace by providing education about the great benefits of peace between fellow believers through calls for peace and real examples in everyday life through social interactions between people. show tolerance and mutual respect that need to be fostered. So that this makes Indonesian Muslims become role models and references for other countries in creating and maintaining world peace. In this study the author uses qualitative research with a library research approach and is descriptive in nature, where the writer wants to reveal more deeply the position of Indonesian Muslims has a significant influence in the realization of world peace. The result of this study is that efforts to participate in creating world peace are carried out by collaborating through related parties, such as government elements by giving attention and helping resolution to countries experiencing conflict, elements of Islamic organizations, such as NU, Muhammadiyah and others by providing support. and take a religious cultural approach to countries experiencing conflict and give conviction to people around the world that Islam is very supportive of world peace. Keywords: Significance, Indonesian Muslims, World Peace
\end{abstract}

\begin{abstract}
Abstrak: Pembahasan ini mengenai bagaimana posisi umat Islam Indonesia dalam kacamata global atau dunia dalam ikut berkontribusi dalam menciptakan perdamaian dunia pada umumnya dan khususnya di negara negara yang berkonflik antar sesama negara Islam. Tidak dapat dipungkiri bahwa posisi umat Islam Indonesia jika dilihat dalam sudut pandang internasional memiliki posisi strategis, karena Indonesia merupakan negara dengan jumlah pemeluk agama Islam terbanyak di dunia. Sehingga posisi ini memiliki potensi dan kekuatan untuk bisa memberikan ikut kontribusi secara nyata dalam menciptakan perdamaian dunia dengan jalan memberikan edukatif akan besarnya manfaat perdamaian antar sesama umat melalui seruan-seruan perdamaian dan contoh-contoh nyata dalam kehidupan sehari-hari melalui interaksi sosial antara sesama dengan menunjukkan sikap toleransi dan saling menghargai yang perlu terus dibina. Sehingga hal tersebut menjadikan umat
\end{abstract}

Belajea: Jurnal Pendidikan Islam Vol. 5, No 2, 2020; 263-276

p-ISSN 2548-3390; e-ISSN 2548-3404, DOI:10.29240/belajea.v5n2.1741

http://journal.iaincurup.ac.id/indek.php/belajea 
264 | Belajea: Jurnal Pendidikan Islam, Vol. 5, No. 2, 2020

Islam Indonesia menjadi role model dan rujukan bagi negara lain dalam mencipatkan dan melestrasikan perdamaian dunia. Dalam telaah ini penulis menggunakan penelitian kualitatif dengan pendekatan studi pustaka (library research) dan bersifat deskriptif, dimana penulis ingin mengungkap lebih dalam posisi umat Islam Indonesia memiliki pengaruh yang signifikan dalam terwujudnya perdamaian dunia. Hasil dari telaah ini adalah upaya agar ikut menciptakan perdamaian dunia dilakukan dengan bekerjasama melalui pihak terkait, seperti elemen pemerintah dengan cara memberikan perhatian dan membantu penyelesaian kepada negaranegara yang mengalami konflik, elemen organisasi Islam, seperti NU, Muhammadiyah dan lainnya dengan cara memberikan dukungan dan melakukan pendekatan kultural keagamaan terhadap negara-negara yang mengalami konflik dan memberi keyakinaan kepada umat di seluruh dunia bahwa Islam sangat mendukung akan perdamaian dunia.

Kata kunci: Signifikansi, Muslim Indonesia, perdamaian dunia

\section{Pendahuluan}

Misi kelahiran Islam ke dunia juga sangat jelas melalui ayat al-Qur'an bahwa Nabi Muhammad diutus ke dunia tidak lain sebagai rahmat bagi sesama ${ }^{1}$. Sebagai agama rahmat, tentu Islam sangat mengutuk keras prilaku kekerasan. Islam mengajarkan umatnya mengedepankan cara-cara damai dialogis dalam menyelesaikan setiap persoalan. ${ }^{2}$

Tidak dapat dipungkiri bahwa Muslim Indonesia memiliki posisi atau peran yang signifikan dalam ikut membantu mewujudkan perdamaian dunia. Hal ini tidak lepas dari posisi Muslim Indonesia yang secara kuantitas merupakan muslim dengan jumlah pemeluk agama Islam terbanyak dibandingkan dengan negara-negara lainnya dan secara letak geografis Indonesia terdiri dari beberapa pulau sehingga hal ini menjadi rujukan atau contoh bagi negara negara lain. Selain itu juga peran ulama' di Indonesia memiliki semangat dan perjuangan yang kuat dalam mewujudkan perdamaian dunia.

Kontribusi perdamaian dunia yang dilakukan Muslim Indonesia tidak hanya dilakukan ke negara-negara yang sedang memiliki konflik namun juga seruan-seruan perdamaian ke seluruh negara di belahan dunia. Selain itu juga ikut andil dalam menangani konflik-konflik yang terjadi di dalam negeri Indonesia sendiri. Apalagi di Indenesia terdiri dari berbagai agama, suku dan ras, hal ini menjadi rawan terjadinya konflik antar daerah jika tidak adanya dorongan dari pemuka agama dan pemerintah akan pentingnya perdamaian dan sikap toleransi di antara umat beragama.

1 Baca QS. al-Anbiyâee [21]: 107 "Dan tiadalah kami mengutus kamu (Muhammad), melainkan untuk (menjadi) rahmat bagi semesta alam"

${ }^{2}$ Said Aqil Siradj Menggagas Theology Perdamaian Sunni Syiah di Indonesia. Teosofi-Volume 3 Nomor 2 Desember 2013 hlm 335 
Sebagai contoh terciptanya perdamaian di Indonesia karena terjadinya beberapa konflik di daerah antara lain: Kesepakatan damai bagi Muslim-Kristen Poso dalam Malino I (2001) dan Muslim-Kristen Maluku dalam perjanjian damai Malino II (2002) melibatkan banyak tokoh Muslim baik dari ormas Islam, seperti Muhammadiyah, NU dan lembaga pesantren maupun pemerintah yang direpresentasikan oleh Departemen Agama, Departemen Sosial dan Majelis Ulama Indonesia. Mereka secara intens melakukan negosiasi dan komunikasi untuk upaya perdamaian di Poso dan Maluku dengan tokoh-tokoh Kristen. Demikian juga dengan kerusuhan di Solo (1998), di Situbondo dan Tasikmalaya (1996) yang melibatkan negosiasi dan komunikasi dengan etnis dan agama yang berbeda, yaitu masyarakat Tionghoa dan Kristen karena target kerusuhan adalah pertokoan milik pengusaha Tionghoa, juga Gereja dan sekolah Kristen ${ }^{3}$.

Hal ini menunjukkan betapa pentingnya terus mewujudkan perdamaian, karena dengan adanya tekad perdamaian maka akan meminimalisir terjadinya konflik-konflik di antara umat beragama di seluruh penjuru dunia. Hal ini menjadi ketertarikan bagi penulis ingin menggali lebih dalam tentang peran signifikan Muslim Indonesia dalam mewujudkan perdamaian pada bingkai konteks perdamaian dunia.

Dan jika membahas perdamaian dunia akan selalu menarik, karena dinamika perkembangan umat di dunia sangat beragam dan masih sering terjadi konflik disebabkan kuatnya ideologi masing-masing umat, sehingga hal ini perlu adanya persepsi yang sama dan kesadaran bersama akan pentingnya perdamaian yang terjalin di antara umat dan tidak ada yang dirugikan bagi semua pihak.

\section{Metode Penelitian}

Dalam telaah atau pembahasan ini penulis menggunakan penelitian kualitatif dengan pendekatan studi pustaka (library research) dan penelitian ini bersifat deskriptif. Penulis akan menggali data-data berkenaan dengan signifikansi umat Islam atau muslim Indonesia dalam konteks perdamaian dunia yang berupa referensi dari buku, jurnal atau sumber lainnya dan langkah selanjutnya menganalisisnya.

\section{Hasil dan Pembahasan}

1. Muslim atau Umat Islam

Kata umat dalam kamus bahasa Indonesia berarti para penganut (pemeluk, pengikut) suatu agama; penganut nabi. Sehingga bisa dikatakan jika

${ }^{3}$ Badrus Soleh. Resolusi Konflik di Asia Tenggara: Pengalaman Muslim Indonesa. Epsiteme Vol 12 no.1 2017 hlm 33-34 
orang memeluk suatu agama, maka orang tersebut sudah dinamakan bagian dari umat dari suatu agama tersebut.

Sedangkan Islam menurut para ahli bahasa arab menyatakan bahwa kata Islam berasal dari kata aslama yang berarti patuh dan berserah diri. Kata ini berakar dari kata Silm, berarti selamat sejahtera dan damai. Orang yang menyatakan dirinya Islam atau berserah diri, tunduk dan patuh kepada kehendak pencipatnya disebut Muslim. Kedua asal kata Islam, aslama dan silm mempunya hubungan pengertian. Yakni, bagi mereka yang ingin hidupnya selamat sejahter dan damai (salam), mereka harus menyerahkan diri kepada Tuhan (aslama) ${ }^{4}$. Dari pengertian Islam ini menunjukkan Islam sangat mengedepankan perdamaian karena Islam sendiri mempunyai makna damai. Sehingga menjadi hal yang aneh dan tidak perlu di contoh jika ada sekelompok orang yang mengatasnamakan kelompok dari Islam namun membuat kekacauan dan fitnah menebar kebencian, hal ini jelas tidak mencerminkan nilai-nilai perdamaian dari makna Islam itu sendiri.

Islam sebagai agama rahmat, mengajarkan nilai-nilai teologi perdamaian. Pada prinsipnya tidak ada kaitan antara kekerasan dan agama. Kekerasan adalah fenomena politik dan sosialAgama secara nyata mengajak umat manusia menjaga perdamaian dengan sesama sebagai jalan hidup yang membahagiakan ${ }^{5}$. Kekerasan muncul akibat persoalan sosial politik yang kemudian dilarikan pada ranah teologis. Hal ini dilakukan sebagai upaya menarik simpati dan empati banyak orang agar dirinya mendapat dukungan. Contoh di masa lalu bagaimana konflik Sunnî-Shî,,ah terjadi akibat perebutan kekuasaan. Sehingga persoalan politik itu ditarik ke ranah teologis. Akibatnya kemarah umat Islam semakin banyak dan membara. ${ }^{6}$

2. Perdamaian

Sikap perdamaian dan persaudaraan dalam menghargai hak-hak asasi manusia harus ditegakkan untuk mencapai persatuan dan kesatuan umat manusia. Sebab persatuan yang kuat akan menimbulkan kekuatan dan menghindari kehinaan dan kelemahan. Dasar dan faktornya ada empat, yaitu agama, hubungan kekerabatan, persaudaraan, dan perbuatan baik. ${ }^{7}$ Agama Islam sangat menjunjung tinggi perdamaian dan kemanusiaan dalam rangka menjalin Ukhuwah Islamiah dan mencegah permusuhan sebab Rasulullah

${ }^{4}$ Moh. Nur Hakim. Metodologi Studi Islam ( (Malang:UMM Press, 2005) hlm 32

5 Asghar Ali Engineer, Liberalisasi Teologi Islam: Membangun Teologi Damai dalam Islam (Yogyakarta: Alinea, 2004), hlm 183.

${ }^{6}$ Said Agil Siradj ... hlm 333

7 Abu al-Hasan Ali al-Bashr al-Mawardi, Etika Agama dan Dunia. Memahami Hakikat Beragama dan Berinteraksi di Dunia, (Bandung: Pustaka Setia, 2003), hlm 123. 
Saw berpesan kepada para sahabatnya untuk saling membantu dan tidak bermusuhan.

Rasulullah menyatakan dalam sabdanya: dengarkanlah kata-kataku dan camkanlah dalam hatimu! ketahuilah bahwa setiap muslim itu saudara bagi setiap muslim lainnya, babwa karena itu sekarang kalian merupakan satu umat. Kata-kata yang amat mengesankan ini, yang diucapkan nabi dalam perjalanan hijrahnya yang terakhir (hajjatul wada) menuju Mekkah tidak lama sebelum wafatnya. Merangkum salah satu dari cita-cita Islam yang paling luhur dan tekanan ajarannya yang paling kuat. Persaudaraan Islam adalah suatu realitas. ${ }^{8}$

Islam sendiripun turun pertama kali dengan misi rabmatan lil Alamin (karunia bagi seluruh alam). Artinya, Islam sejak awal menekankan pemeluknya untuk menghargai pemeluk agama lain dan mengakuinya sebagai mitra dalam penciptaan perdamaian. Selain itu, kata Islam yang berakar kata sama dengan salam pun, maknanya adalah kedamaian. Maka, setelah manusia membuktikan pengabdiannya lewat ibadah kepada Allah, mereka juga harus mempraktekkannya dengan menebarkan perdamaian pada semua umat manusia. Untuk menerangkan bagaimana Islam menjawab pertanyaan tentang perdamaian, cukuplah dengan menerangkan beberapa kenyataan dan fakta yang terdapat dalam Islam. Perdamaian dan Islam berasal dari salah satu akar kata yang sama sehingga boleh juga dikatakan bahwa Islam adalah sinonimnya dari perdamaian. ${ }^{9}$

Salah satu dari sembilan puluh sembilan Asma Allah adalah asSalam (Maha Damai). Setiap lafąh (kata) yang diucapkan umat Islam dalam setiap shalat yang lima kali sehari semalam adalah kata-kata perdamaian. Ucapan pertama ketika selesai dari salat adalah "salam" (perdamaian). Ketika umat Islam saling berjumpa pun mengucapkan ucapan "salam” (perdamaian). Demikian juga, kata sifat dari muslim artinya perdamaian dan surga dalam Islam adalah suatu tempat yang damai (Darus Salam). Semua ini memperlihatkan betapa mendasar dan kuatnya pengertian perdamaian dalam Islam. Setiap orang yang mencapai Tuhan melalui Islam, sama sekali tidak ada kecewa untuk mendapatkan kedamaian bersama Tuhannya, Allah aza wa jalla, damai dengan dirinya, dan damai bersama orang-orang yang mau mengikutinya. ${ }^{10}$

Islam sebagai agama terakhir mengajarkan nilai-nilai luhur tentang 283-284.

${ }^{8}$ Huston Smith, Agama-Agama Manusia, (Jakarta: Yayasan Obor Indonesia, 2004), hlm.

'Supriyanto. Perdamaian dan kemanusiaan dalam pandangan Islam. Kalam: Jurnal Studi Agama dan Pemikiran Islam Vol. 7, No. 2, Desember 2013 hlm 311

${ }^{10} \mathrm{Ibid}$ 
sikap perdamain. Islam berkembang pesat ke berbagai penjuru dunia tidak lain karena Islam menegakkan prinsip-prinsip perdamaian. Peperangan Islam di masa lalu itu sebagai bentuk pertahanan agar orang-orang Islam bisa selamat, bukan sebagai jalan menyerang umat tertentu karena berbeda keyakinan. Seandainya Islam menjadikan peperangan sebagai jalan penyebaran dakwa Islam, niscaya Islam tidak akan berkembang pesat seperti hari ini. Sejatinya tidak ada agama yang bisa berkembang pesat melalui pertumpahan darah dan terror. Karena itulah dakwah dalam Islam dilakukan secara damai dan santun. Selama ini mereka yang melakukan dakwah amar ma'rûf nahy munkar melalui kekerasan itu tak lebih dari egoisme diri karena salah dalam membaca sejarah dan menafsiri teks al-Qur ân dan Hadîth ${ }^{11}$

Dengan demikian jelaslah bahwa dalam ajaran Islam menyeru adanya perdamaian bukan sebaliknya. Oleh karena itu umat Islam yang benar-benar mengamalkan ajaran Islam, maka selalu menjaga dan melestarikan perdamaian di dunia ini.

3. Signifikansi umat Islam Indonesia dalam konteks perdamaian dunia

Maksud kata signifikansi dalam pembahasan ini adalah sejauh mana signifikan atau seberapa penting posisinya. Sehingga jika dirangkai dengan kata seterusnya, maka pembahasan ini bermaksud menganalisis sejauh mana signifikan atau seberapa pentingnya posisi umat Islam Indonesia dalam pandangan dunia ikut memiliki andil atau kontribusi dalam mewujudkan perdamaian dunia

Untuk mendapat gambaran jelas akan signifikannya umat Islam Indonesia ikut berkontribusi dalam mewujudkan perdamaian dunia, maka penulis uraikan beberapa peristiwa yang terjadi di beberapa negara dan tokoh yang berkontribusi mengupayakan solusi pemecahannya, antara lain:

a. Kamboja vs Khmer Merah

Terjadinya konflik antara pemerintah kamboja dengan kelompok Khmer Merah. Khmer Merah (seringkali disebut Khmer Rouge) adalah sayap militer Partai Komunis Kamboja yang beraliran Maois. Partai Komunis Kamboja dibentuk pada tahun 1968 sebagai cabang dari Partai Rakyat Vietnam dari Vietnam Utara. Partai ini menjadi partai berkuasa di Kamboja (kemudian berganti nama menjadi Kamboja Demokratik) dari tahun 1975 hingga 1979, dipimpin oleh Pol Pot, Nuon Chea, Ieng Sary, Son Sen, dan Khieu Samphan. Selama Perang Vietnam Kedua (19551975) bersekutu dengan Vietnam Utara, Viet Cong, dan Pathet Lao

${ }^{11}$ Said Aqil Siradj ... hlm 335 
melawan kekuatan anti-komunis yang terdiri dari Vietnam Selatan dan Amerika Serikat.

Pada tahun 1960-an dan 1970-an, Khmer Merah melaksanakan perang gerilya melawan rezim pimpinan Marsekal Lon Nol. Pada bulan April 1975, Khmer Merah yang dipimpin oleh Pol Pot berhasil menggulingkan kekuasaan dan mendirikan negara Kamboja Demokratik. Ia memerintah sampai tahun 1979 dan dalam masa pemerintahannya, terjadi pembunuhan massal terhadap kaum intelektual dan lain-lain. Setelah diusir oleh orang Vietnam, Khmer Merah masih bercokol di daerah hutan di Kamboja. ${ }^{12}$

Yang menjadi mediator atau orang yang mendamaikan konflik yang berkepanjangan di kamboja ini adalah Ali Alatas (menteri luar negeri masa itu) pada tahun 2001. Inisiatif pertama upaya mediasi yang dihadiri perwakilan kelompok yang bertikai di Cambodia, yaitu HRH Samdech Norodom Sihanouk-mewakili pemerintah Cambodia-dan H.E. Mr. Hun Sen-mewakili Kelompok Khmer Merah-yang dilakukan di Bogor pada 25-28 Juli 1988, dengan istilah Jakarta Informal Meeting. Dalam pertemuan ini Ali Alatas menyatakan bahwa "any settlement, to be just and durable should be attained through political means and not by force of arms". Setelah melalui beberapa pertemuan, perjanjian perdamaian dilakukan di Paris dalam The Paris International Conference on Cambodia, 23 Oktober 1991. Upaya perdamaian ini melibatkan juga PBB dan ASEAN sebagai organisasi internasional yang ikut menfasilitasi proses rekonsiliasi.

b. Filipina vs MNLF

Terjadinya konflik antara pemerintah Filipina dan MNLF. Front Pembebasan Nasional Moro (bahasa Inggris: Moro National Liberation Front, disingkat MNLF) adalah sebuah organisasi politik sekesionis di Filipina yang didirikan pada 1972. Kelompok tersebut mulanya adalah sebuah grup pecahan dari Gerakan Kemerdekaan Muslim. MNLF merupakan salah satu organisasi utama dari golongan separatis Moro selama sekitar dua dekade dari 1970an. Kelompok tersebut berjuang demi kemerdekaan Bangsamoro yang meliputi wilayah Mindanao, Palawan dan Sulu. ${ }^{13}$

Selanjutnya, dalam menjembatani konflik antara MNLF (Morro National Liberation Front) dan Pemerintah Filipina, Ali Alatas memainkan peran penting dalam kesepakatan damai antara milisi Muslim

${ }^{12}$ Diakses di Wikipedia, 31-10-2019

${ }^{13}$ Diakses di Wikipedia, 31-10-2019 
dan pemerintah Filipina. Hingga saat ini MNLF tetap menaati kesepakatan yang telah dilakukan dengan pemerintah. Atas permintaan kedua belah pihak yang bertikai, Ali Alatas memimpin proses rekonsiliasi yang dihadiri oleh Pemerintah Republik Filipina (GRP, Government of the Republic of the Philippines) dan Front Pembebasan Nasional Morro (MNLF, the Morro National Liberation Front) di Istana Bogor, 14 April 1993. Dalam proses rekonsiliasi, Ali Alatas menyatakan bahwa "Negosiasi yang baik membutuhkan semangat konsiliasi, konsesi yang saling menguntungkan dan keinginan untuk mencapai perdamaian dan solusi yang adil. ${ }^{14}$

Upaya perdamaian ini melanjutkan semangat Persetujuan Damai Tripoli 1976, dengan menciptakan otonomi luas di bawah integritas territorial dan kedaulatan Filipina. Setelah lebih dari 70 kali pertemuan informal, disepakati sembilan area Otonomi: Perdamaian Nasional, Tentara Keamanan Regional, Pendidikan, Sistim Ekonomi dan Keuangan, Hasil pertambangan dan mineral, Sistem Administrasi, Representasi dalam Pemerintah Nasional, Lembaga legislatif dan eksekutif, dan peradilan dan pengenalan syariah Islam. Pada 1996, melalui peran utama Menlu Ali Alatas dan dukungan OIC disepakati perjanjian damai antara PemerintahFilipina dan Morro National Liberation Front (MNLF).

Nahdlatul Ulama menjadi salah satu Organisasi Masyarakat Sipil yang memiliki peran utama dalam mendampingi MNLF dan Muslim di Filipina Selatan untuk memikirkan pembangunan ekonomi dan sosial politik, sesuatu yang lebih bermakna bagi masyarakat Mindanao yang masih dihantui kemiskinan dan pendidikan yang rendah akibat konflik yang berkepanjangan. ${ }^{15}$

c. Filipina vs MILF

Front Pembebasan Islam Moro (bahasa Inggris: Moro Islamic Liberation Front/MILF) adalah kelompok militan Islam yang berpusat di selatan Filipina. Daerah tempat kelompok ini aktif dinamai Bangsamoro oleh MILF dan meliputi bagian selatan Mindanao, kepulauan Sulu, Palawan, Basilan dan beberapa pulau yang bersebelahan. MILF didirikan oleh Salamat Hashim, yang dipengaruhi oleh Sayyid Qutb. Salamat meninggal pada Juli 2003 dan digantikan oleh Al Haj Murad Ebrahim. ${ }^{16}$

Kesepakatan damai antara MILF dan Pemerintah Filipina yang juga melibatkan Pemerintah dan Masyarakat Sipil Republik Indonesia.

\footnotetext{
${ }^{14}$ Badrus Soleh... hlm 39

${ }^{15}$ Ibid ... hlm 40

${ }^{16}$ Diakses di Wikipedia , 1-11-2019
} 
Kementerian Luar Negeri RI dan Muhammadiyah - yang secara resmi menjadi salah satu International Contact Group (ICG) ikut mengawasi proses perjanjian damai. Professor Din Syamsuddin sebagai ketua PP Muhammadiyah memiliki peran aktif dalam negosiasi perdamaian dan upaya implementasinya. Pada tahun 2012 ditandatangani Bangsamorro Basic Law (BBL), perjanjian damai antara Pemerintah Filipina dan Morro Islamic Liberation Front (MILF). ${ }^{17}$

d. Internal dalam Negeri Indonesia

Muhammad Yusuf Kalla, menjadi salah satu ikon penting dalam proses perdamaian baik dalam negeri maupun luar negeri. Kesepakatan damai antara Muslim dan Kristen Poso dalam Malino I (2001) dan Muslim-Kristen Maluku dalam Malino II (2002) tidak lepas dari peran utama Yusuf Kalla dalam mediasi dan rekonsiliasi komunitas Muslim dan Kristen. Perjanjian damai sangat berpengaruh dalam menurunnya eskalasi bentrokan antardua komunitas berbeda agama. Bahkan ketika masih menjabat Wakil Presiden, Yusuf Kalla melakukan pencegahan aksi kekerasan menyusul kontak senjata antara Brimob Polri dan kelompok Tanah Runtuh Poso. ${ }^{18}$

Dengan pengalaman mediasi dalam negeri, Yusuf Kalla yang menjabat Wakil Presiden mendampingi Presiden Susilo Bambang Yudhoyono sebagai hasil Pemilu 2004 mencoba mendekati tokoh-tokoh Gerakan Aceh Merdeka (GAM) untuk menghentikan upaya separatisme dengan kembali ke pangkuan Ibu Pertiwi, Negara Kesatuan RepublikIndonesia. Akhirnya dengan beberapa pertemuan negosiasi yang didukung dan difasilitasi oleh Uni Eropa, GAM dan Republik Indonesia melakukan kesepakatan damai pada 2005. Kesepakatan ini memberi kesempatan para pimpinan dan anggota GAM untuk aktif dalam politik dan kegiatan lain demi terwujudnya perdamaian dan kemakmuran masyarakat Aceh. ${ }^{19}$

Dari uraian beberapa peristiwa konflik di berbagai negara dan cara yang digunakan dalam mendamaikannya, bisa dipahami bahwa Pendekatan Ali Alatas dan Yusuf Kalla tentu saja tidak lepas dari karakter Muslim Indonesia yang moderat dan membuktikan Islam sebagai berkah bagi alam

\footnotetext{
${ }^{17}$ Badrus Soleh ... hlm 41

${ }^{18}$ Ibid hlm 42

${ }^{19}$ Badrus Soleh...hlm 43
} 
semesta. Yusuf Kalla seringkali merepresentasikan sebagai tokoh Nahdlatul Ulama dari Sulawesi Selatan. ${ }^{20}$

Indonesia juga memiliki tokoh-tokoh Muslim yang aktif dalam perdamaian baik di kalangan masyarakat Indonesia maupun lintas negara. Abdurrahman Wahid dan Ahmad Syafi'i Ma'arif adalah di antara mereka yang aktif dalam pertemuan lintas agama dan negara untuk mewujudkan perdamaian global. Keduanya masing-masing pernah menjadi pemimpin tertinggi ormas Islam NU dan Muhammadiyah, yang telah menjaga tradisi toleransi dan perdamaian sejak awal didirikan khususnya melalui lembaga pendidikan.Karena itu, tradisi perdamaian dan pola mediasi lintas agama tidak terlepas dari pengalaman mereka dalam memimpin dua ormas Islam terbesar di Indonesia tersebut.

Sebagai penduduk mayoritas, Muslim Indonesia juga aktif melakukan mediasi dan perdamaian antara Muslim di Thailand Selatan dan pemerintah Thailand, serta antara Muslim di Filipina Selatan dan pemerintah Filipina, di antaranya adalah Hasyim Muzadi dan beberapa tokoh NU. Melalui pendekatan Muslim tradisional dan tradisi Melayu, Hasyim Muzadi dan beberapa tokoh NU melakukan komunikasi aktif dengan tokoh-tokoh pesantren dan madrasah di kedua wilayah. ${ }^{21}$

Sehingga bisa digarisbawahi bahwa pada level masyarakat sipil Ahmad Syafi'i Ma'arif, M. Din Syamsuddin dan KH Hasyim Muzadi aktif dalam upaya perdamaian di Filipina Selatan saat ini ketika MILF dan Pemerintah Filipina melakukan kesepakatan perdamaian, dan mendekatkan raja dan pimpinan pemerintah Filipina dengan kelompok pemberontak di Thailand Selatan melalui pendekatan kultural keagamaan. ${ }^{22}$

Disamping itu, KH. Hasyim Muzadi juga memiliki perhatian terhadap kondisi yang terjadi di Timur tengah, sehingga beliau banyak melakukan perjalanan ke timur tengah dalam rangka memberikan kontribusi untuk terciptanya perdamaian di kawasan itu. Apalagi kawasan timur tengah adalah rata-rata negara Islam dan menjadi pusat dan asal Islam yang dianut oleh umat Islam. Namun umat Islam di sana tercabik-cabik. Di palestina Hamasfatah pecah dan saling menyerang, Sunni-Syi'ah di Iraq mengarah ke

\footnotetext{
${ }^{20}$ Ibid hlm 44

${ }^{21}$ Ibid ... hlm 46

${ }^{22}$ Badrus Soleh ... hlm 50
} 
peperangan. Di Lebanon-Syria, Sunni dengan Sunni juga pecah setelah terbunuhnya PM Hariri. ${ }^{23}$

Dengan melihat kiprah dari tokoh-tokoh muslim Indonesia di kancah internasional, menunjukkan kontribusi yang besar terhadap terwujudnya perdamaian di negera-negara yang berkonflik tersebut. Sehingga muslim Indonesia mempunyai posisi yang signifikan dalam membantu terciptanya perdamaian.

Sebetulnya, hampir dipastikan bahwa semua negara dan agama sepakat agar warga dan umatnya menghindari tindak kekerasan. Semuanya pasti setuju dengan terciptanya perdamaian dunia yang telah lama dinantinantikan. Ideologi perang dan kekerasan di masa lalu, terbukti banyak menimbulkan kebangkrutan dan kemunduran peradaban. Oleh karena itu, isu terorisme memojokkan umat beragama dan negara berkembang, haruslah dikaji dan dikritisi secara mendalam. ${ }^{24}$

Berikut ini beberapa cara dalam menyelesaikan konflik antar pemeluk agama dalam mewujudkan perdamaian dunia

1) Manajemen Toleransi

Tokoh yang menjalankan manajemen teleransi dengan baik adalah KH Hasyim Muzadi. Menurut pandangan beliau agar perdamaian tercipta, beliau memandang penting: "ini dapat diwujudkan melalui sejumlah pijakan norma dan prinsip. Di antaranya prinsip anti kekerasan, keadilan, kemerdekaan, moderasi, toleransi, kesimbangan, musyawarah, dan kesamaan. ${ }^{25}$ Gagasan, ide dan gerakan KH Hasyim Muzadi dalam toleransi beragama didengar oleh umat beragama dunia. Kiprahnya Kian diakui oleh dunia setelah beliau terpilih sebagai presiden World Conference on Religion and Piece (WCRP) sebuah organisasi lintas agama yang menghimpun tokoh-tokoh berbagai agama dari seluruh dunia dalam sebuah konferensi yang dihadiri 600-an tokoh dari 20 agama dari 100 negara, di Kyoto Jepang, 25-26 Agustus 2006.

Maksud dari manajemen toleransi adalah bagaimana mengelola toleransi sesuai dengan semestinya dan tempatnya serta tidak ada pihak yang dirugikan. Sehingga semua orang merasa dihormati dan tidak merasa ada yang dihinakan.

${ }^{23}$ Mukhlas Syarkun \& Moh. Arifin. Jembatan Islam-Barat dari sunan Bonang ke Paman Sam. (Jogjakarta: Penerbit PS, 2015 )hlm 246

${ }^{24}$ Supriynto ... hlm 310

${ }^{25}$ Ahmad Millah Hasan. Biografi A. Hasyim Muzadi. (Depok: keira Publishing, 2018) hlm 
Dengan demikian hal ini dipahami bahwa manajemen toleransi memiliki manfaat yang luar biasa untuk terciptanya perdamaian di antara pemeluk agama. Sehingga keberlangsungan dalam menjalankan rutinitas ibadah keagamaan sehari-hari menjadi lebih nyaman dan merasa aman.

Dalam perilaku sehari-hari, toleransi akan menghasilkan keseimbangan dan dialog. Dalam masyarakat yang multi agama (keyakinan) dan budaya, dengan tawassuth dan I'tidal, seorang muslim akan bisa bersikap seimbang antara keyakinan dan toleransi, ini menurut pandangan KH Hasyim Muzadi.

Menurut KH Hasyim Muzadi, keyakinan (beragama) tanpa toleransi akan mengarah pada eksterisme dan ekslusivisme. Sebalinya, toleransi tanpa keyakinan akan mengakibatkan seseorang mudah tertipu dan kebingunan.seorang muslim akan menganggap toleransi sebagai bagian yang tak terpisahkan dengan keyakinan. Keseimbangan disini bukan berarti 50 persen keyakinan dan 50 persen toleransi. Tapi, semuanya, keyakinan dan toleransi harus penuh 100 persen. ${ }^{26}$

2) Membumikan konsep Islam rahmatan lil 'alamin

Secara etimologi, Islam berarti damai. Sedangkan rahmatan lil 'alamin berarti kasih saying bagi semesta alam. Maka yang dimaksud dengan Islam rahmatan lil alamin adalah islam yang kehadirannya di tengah kehidupan masyarakat mampu mewujudkan kedamaian dan kasih sayang bagi manusia maupun alam. Rahmatan lil alamin adalah istilah qur'ani. Istilah itu sudah terdapat dalam al-Qur'an, sebagaimana firman Allah dalam surah al-anbiya' ayat 107: "dan tiadalah kami mengutus kamu, melainkan untuk (menjadi) rahmat bagi semesta alam (rabmatan lil alamin)" 27

Rahmat dalam konteks rahman adalah bersifat amma kulla syai, meliputi segala hal, sehingga orang-orang non muslim pun mempunyai hak kerahmatan. Rahim adalah kerahmatan Allah yang hanya diberikan kepada orang Islam. Jadi Rahim adalah khoshshun lil muslim.

Karena itu, menurut KH. Hasyim Muzadi, apabila Islam dilakukan secara benar, Rahman dan Rahim Allah akan turun semuanya. Dengan demikian berlaku hukum sunnatullah: baik muslim maupun nonmuslim, kalau mereka melakukan hal-hal yang diperlukan oleh ke-rahman-an, merak akan mendapatkannya. ${ }^{28}$

${ }^{26}$ Ibid ... hlm 502

${ }^{27}$ Ahmad Millah hasan ... hlm 258

${ }^{28} \mathrm{Ibid}$ 
Menurut penulis dua cara diatas merupakan jawaban atas kondisi antar pemeluk agama saat ini yang mengalami pasang surut antar pemeluk agama, sehingga perlu solusi untuk mengatasinya dengan jalan adanya sikap toleransi dan bagi umat Islam untuk lebih menjiwai dan mengamalkan konsep Islam Rahmatan lil 'alamin dalam bingkai kehidupan sehari-hari.

\section{Penutup}

Dari uraian diatas dapat disimpulkan bahwa umat Islam atau muslim Indonesia memiliki peran atau posisi yang signifikan, hal ini bisa dilihat dengan adanya tokoh atau ulama Indonesia yang ikut berkontribusi dalam terwujudnya perdamaian dunia.

Bentuk kontribusi dalam upaya ikut menciptakan perdamaian dunia dilakukan dengan beberapa elemen:

a. Melalui elemen pemerintah dengan cara mendelegasikan seorang pejabat penting yang merepresentasikan atas nama pemerintah untuk memberikan perhatian dan membantu penyelesaian kepada negara-negara yang mengalami konflik

b. Melalui elemen organisasi Islam, seperti NU, Muhammadiyah dan lainnya melalui perwakilannya dengan cara memberikan dukungan dan melakukan pendekatan kultural keagamaan terhadap negara-negara yang mengalami konflik.

Sedangkan beberapa cara dalam upaya untuk menyelesaikan konflik antar pemeluk agama dalam mewujudkan perdamaian dunia yakni manajemen toleransi dan membumikan konsep Islam rahmatan lil 'alamin.

\section{Bibliografy}

al-Hasan, Abu Ali al-Bashr al-Mawardi,. Etika Agama dan Dunia. Memahami Hakikat Beragama dan Berinteraksi di Dunia,. (Bandung: Pustaka Setia, 2003)

Ali, Asghar Engineer, . Liberalisasi Teologi Islam: Membangun Teologi Damai dalam Islam. (Yogyakarta: Alinea. 2004)

Aqil, Said Siradj menggagas theology Perdamaian Sunni Syiah di Indonesia. (TeosofiVolume 3 Nomor 2 Desember2013)

Millah, Ahmad Hasan. Biografi A. Hasyim Muradi. (Depok: Keira Publishing, 2018) 
276 | Belajea: Jurnal Pendidikan Islam, Vol. 5, No. 2, 2020

Nur, Moh. Hakim. Metodologi Studi Islam. (Malang:UMM press. 2005)

Smith, Huston, Agama-Agama Manusia,. (Jakarta: Yayasan Obor Indonesia, 2004)

Soleh, Badrus.. Resolusi Konflik di Asia Tenggara: Pengalaman Muslim Indonesa. (Epsiteme Vol 12 no.1. 2017)

Supriyanto..Perdamaiann dan kemanusiaan dalam pandangan Islam. (Kalam: Jurnal Studi Agama dan Pemikiran Islam Vol. 7, No. 2, Desember 2013)

Syarkun, Mukhlas dan Moh. Arifin.. Jembatan Islam-Barat dari sunan Bonang ke Paman Sam. (Jogjakarta: Penerbit PS. 2015) Wikipedia 